Evaluating the effectiveness of therapy based around Shape Coding to develop the use of regular past tense morphemes in two children with language impairments.

\author{
Amit Kulkarni* \\ Guys \& St. Thomas Community Health Services, UK. \\ Tim Pring \\ City University, UK.

\section{Susan Ebbels} \\ Moor House School, UK. \\ University College London, UK.
}

${ }^{*}$ Corresponding author

Email: amit.kulkarni@nhs.net

This paper is now published as: Kulkarni, A., Pring, T. \& Ebbels, S.H. (2014). Evaluating the effectiveness of therapy based around Shape Coding to develop the use of regular past tense morphemes in two children with language impairments. Child Language Teaching and Therapy, 30: 245-254. http://journals.sagepub.com/doi/abs/10.1177/0265659013514982 


\section{Abstract}

It has been suggested that difficulties with tense and agreement marking are a core feature of language impairment. Hence, studies are required that analyse the effectiveness of intervention in this area, including consideration of whether changes seen in therapy sessions generalise to spontaneous speech. This study assessed the effectiveness of therapy based around Shape Coding in developing the use of the regular past tense morpheme '-ed' in two school aged children with language impairments. It also considered whether participants benefitted from additional generalisation therapy in order to start using target forms in their spontaneous speech. The former was assessed using a sentence completion task and the latter by a conversational task with blind assessors. One participant improved markedly in sentence completion but did not gain in the conversation task until after the generalisation therapy. The other made more modest gains on the sentence completion task and seemed to generalise to the conversation task without recourse to the generalisation therapy. Larger studies are required to confirm these interpretations and determine whether they are applicable to the wider population of children with language impairments.

\section{Keywords}

Language impairment, intervention, school aged, Shape Coding, grammar, morphology.

\section{Introduction}

Children with language impairments form a heterogeneous group with difficulties in various aspects of language (e.g. Conti-Ramsden \& Botting 1999, Ebbels, 2008). These difficulties can significantly impact upon academic and social development (Tomblin et al, 1997). Understanding and use of grammar is a key area of difficulty for some children with language impairments (e.g. Rice \& Wexler 1996, Finestack \& Fey 2009). Difficulties marking the past tense are a key component of such 
problems (e.g. Conti-Ramsden \& Botting 2001, Rice et al 2004). Indeed, various authors have suggested that difficulties in this area may constitute a clinical marker for specific language impairment (SLI) ${ }^{1}$ (e.g. Rice \& Wexler 1996, Rice et al 2004, Marchman et al 1999) or grammatical SLI (G-SLI) ${ }^{2}$ (Van der Lely et al, 2005). A growing body of studies has assessed the effectiveness of intervention in this specific area. Leonard et al (2008) assessed the acquisition of tense and agreement morphemes in 33, 3;0 - 4;8 year old children with SLI. Three treatment conditions were compared, each using focused stimulation and recasting but targeting three different areas: third person singular; auxiliary verbs; general language stimulation. Use of the regular past tense was assessed as a control hence none of the three interventions directly targeted it. None led to significant gains. Two recent studies have directly treated use of the past tense. Seef-Gabriel et al (2012) highlight the need to consider the phonological issues that arise when treating morphological targets. They treated a 5 year old boy with co-occurring speech and language difficulties. Intervention, which focused on the morphology of the regular past tense as the participant had the necessary phonology, involved demonstrating that something was added to the end of the verb (using hand gestures or blocks), auditory bombardment, judgement tasks and production tasks. Following intervention, significant improvement in use of the past tense was observed in picture description tasks and was maintained eight weeks later. Ebbels (2007) assessed the production of past tense morphemes in written tasks following an intervention using Shape Coding, which explicitly teaches the tense rules using a system of arrows as a visual aid (see below for further details on Shape Coding). Six of nine participants, aged 11 to 13 , made significant gains following a class based intervention and two more improved after further intervention in a pair.

The studies mentioned above used a range of therapeutic techniques. In her review of intervention for grammatical impairments, Ebbels (2008) divides approaches into three areas: grammar facilitation

\footnotetext{
${ }^{1}$ See Bishop (2004) for discussion about SLI.

${ }^{2}$ See Van der Lely et al (2005) for discussion about G-SLI.
} 
techniques (e.g. imitation, modelling), acoustically modified speech (e.g. Fast ForWord) and metalinguistic methods (e.g. Colourful Semantics, Shape Coding). She concludes that whilst the evidence in support of acoustically modified speech has several weaknesses, a number of randomised control trials (RCTs) indicate the effectiveness of grammar facilitation techniques for early years and younger school aged children. Studies have also shown that metalinguistic approaches can be effective with school aged children. For example, Ebbels et al (2007) demonstrated the effectiveness of Shape Coding in improving production of verb argument structure in 27 secondary aged pupils (aged $11 ; 0$ to $16 ; 1$ ) with SLI. However, concluding the review, Ebbels (2008) states that further studies using established experimental designs are needed to broaden the research base and to confirm research findings. These studies should target children of different ages, particularly of school aged children, where fewer studies currently exist. They should treat specific areas e.g. regular past tense morphemes, to provide clear evidence that a particular approach works for a particular target. They should also examine whether gains are maintained and generalised to spontaneous speech in different settings with a range of people as this was not always observed in the studies reviewed.

Since that review, further studies have assessed the metalinguistic approach. Finestack \& Fey (2009) showed that a metalinguistic approach (referred to as a "deductive treatment") was more effective than a traditional modelling approach (an "inductive treatment") at teaching novel grammatical inflections to $32,6-8$ year old children with a language impairment. More children benefitted from the deductive approach and maintained their gains. Also, more children generalised their learning to use the novel inflection with different subjects and verbs. However, the study was conducted in controlled conditions and taught the children a novel inflection, hence the authors stress the need to target true grammatical morphemes in more naturalistic conditions. This approach was taken in Motsch \& Riehemann (2008), who assessed the effectiveness of 'Context-Optimisation' 
therapy in supporting the acquisition of grammatical case in 126, 8;6 -10;1 year old German speaking children with SLI. This 'Context Optimisation' approach combined the use of metalinguistic and 'traditional' (e.g. modelling and corrective feedback) methods. Participants' case marking skills increased significantly following intervention and these gains were maintained at a follow up assessment three months later. A third study using a metalinguistic approach, Bolderson et al (2011), used 'Colourful Semantics' (Bryan, 1997) to develop the verb - argument structure of six, 5-6 year old children with language difficulties. Scores on standardised assessments of expressive language and an informal verb-argument assessment all increased post-intervention, but not during the baseline period.

The current study builds on this previous research. It assesses the use of therapy based around Shape Coding in developing the use of the regular past tense in children with language impairments. Following the successes noted above, it is based around a metalinguistic approach, Shape Coding, but also uses grammar facilitation techniques e.g. recasting (see method for further details). It targets school aged children and assesses specific targets (regular past tense) but differs from Ebbels (2007) past tense study in that it targets primary school aged children and spoken language. It considers both maintenance and generalisation to more spontaneous speech. Drawing on Ebbels (2008) review, in which generalisation was only observed in six out of thirteen studies targeting expressive language, it hypothesises that specific work targeting generalisation will be required before it is in evidence. The study is in two phases. Phase one assesses the effectiveness of therapy based around Shape Coding in developing the use of regular past tense morphemes in school with the participants' speech and language therapist. Phase two considers generalisation to spontaneous speech with other people. The study has three experimental hypotheses:

1: Therapy will result in significant improvements in the children's use of regular past tense morphemes at school with the therapist. 
2: The therapy in phase one will not lead to generalised improvements in the use of regular past tense morphemes in spontaneous speech with other people.

3: Specific activities targeting generalisation (in phase two) will lead to generalisation.

\section{Method}

\section{Participants}

Participants were selected from the caseload of a language centre attached to mainstream primary school. Hence the population of interest for the project was defined by the entrance criteria for the language centre: significant difficulty with language skills (more than two standard deviations below the average range in at least two areas of language); speech, language and/or communication skills identified as the main / one of the main areas of need; mainstream curriculum considered accessible with support. Selection followed screening of all children attending the centre to identify candidates for whom work on the past tense was a functional and realistic target. Use of the past tense was then assessed. Inclusion criteria were that the child should use the regular past tense and the auxiliary verb 'do' correctly less than $50 \%$ of the time ('do' was used as a control). Two candidates were identified. Participant A had a diagnosis of language disorder. Participant B had a diagnosis of Autistic Spectrum Disorder (ASD) but assessment suggested that language was his main area of need. Participant A's standard scores were 49 (percentile rank $<0.1$ ) on the Expressive Language Index and 46 (percentile rank $<0.1$ ) on the Language Structure Index of the Clinical Evaluation of Language Fundamentals 4 (CELF 4) (Semel et al, 2006). Participant's B's standard scores were 55 (percentile rank 0.1) on the Expressive Language Index and 54 (percentile rank 0.1) on the Language Structure Index. Receptive Language Index scores were not obtained. Participant A was at the $50^{\text {th }}$ percentile on the Raven's matrices and participant $B$ between the $75^{\text {th }}$ and $90^{\text {th }}$. Both were male. A was $9 ; 4$ when treatment started and had attended the language centre since the age of $6 ; 2$. B was 
$8 ; 11$ when treatment started and had attended the language centre since the age of $4 ; 10$. Both identified and produced /t/ and /d/ consistently on an informal screener.

\section{Assessments}

The Past Tense subtest of the Rice-Wexler Test of Early Grammatical Impairment (TEGI; Rice and Wexler, 2001) was used to assess target structures. The test uses a sentence completion task and has ten regular verbs. A further ten high frequency verbs were added to meet the requirements of the research design. These were chosen on the basis that they were likely to be understood and used by children of the participants' language levels. Assessment showed the participants understood all twenty verbs. See table 1 below for a list of the TEGI regular verbs and the 10 additional regular verbs.

Table 1: 10 TEGI verbs and 10 additional verbs.

\section{TEGI regular verbs}

\section{0 added verbs}

painted, planted, lifted, cleaned, climbed, tied, brushed, kicked, jumped, picked visited, listened, called, tidied, played, carried, cooked, watched, walked, talked

Use of the 20 target verbs in spontaneous speech was assessed by blind assessors using a scripted, semi-structured conversation task. Participants were asked "what did you do at the weekend?" and the assessor noted the form of any target verbs used e.g. regular past, gerund, infinitive. They were then shown Widgit symbols for any of the twenty target verbs not yet used and asked "what about any of these things?" If they still hadn't used all twenty verbs, they were shown a toy and told "this is my friend Ted. He did all the rest of these things - tell me about all of them". Use of any other verbs was not scored. One assessment carried out by each blind assessor was recorded to check consistency. 
Several areas were assessed to identify a suitable control. The auxiliary verb 'do' was chosen. Both participants' scores for 'do' on the auxiliary verb probe of the TEGI were similar to their scores on the past tense probe prior to intervention. As before, ten extra items were added to those in the TEGI. The TEGI+10 assessments were carried out by the first author (who also provided the intervention); the conversation task was carried out by blind assessors. No prompts from the intervention phase were used during the assessments.

\section{Experimental Design}

The study used a within subjects, multiple baseline design with two participants. Participants' performance was assessed prior to therapy over a six week baseline period to ensure performance was stable. This was followed by ten weeks of therapy. The effect of the therapy was measured by comparing change in the use of the target and control structures pre to post therapy. A maintenance period of six weeks was planned followed by five weeks of generalisation therapy to promote the use of targets in the participants' spontaneous speech. This timetable was followed for participant A but not for Participant B. Changes are described in the results section.

In the first phase, therapy aimed to develop the participants' use of regular past tense morphemes on a sentence completion task with the therapist. Each participant was treated on ten of the verbs; $A$ on the ten TEGI verbs and B on the ten additional verbs. All the verbs were retested. Improvement on the untreated verbs would therefore indicate that participants had acquired the rule that governs regular verbs and were not learning item by item. Participants were not expected to improve on the conversation task during phase one. Phase two consisted of activities to achieve this. Therapy activities are described below.

\section{Therapy}


Therapy was based around Shape Coding. Shape Coding identifies phrases, parts of speech and verb tenses using a system of shapes, colours and arrows. For example, verbs are underlined in blue $^{3}$ and placed in a hexagon shape, along with any verb arguments. The verb's tense is shown using a 'down arrow'. The arrow is on the left of the verb if the action is in the past or in the middle if in the present (see example below).

Figure 1. Examples of Shape Coding

e.g
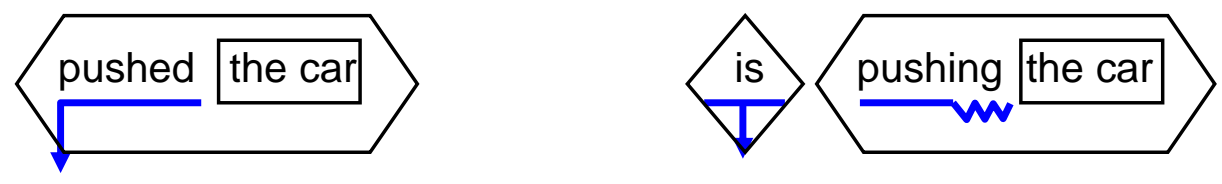

Explicit discussion of grammatical rules combined with their visual representation allows children to use their general cognitive and visual processing skills to support their processing of language. See Ebbels (2007), for further details on Shape Coding.

Intervention incorporated the principles of grammar facilitation suggested by Fey et al (2003). Following their recommendations, therapy targeted both spoken and written language in a range of activities e.g. conversation, sentence completion tasks on worksheets; used SMART (Doran, 1981) long, short and session goals; maximized opportunities for identification and production of target forms, using Shape Coding to highlight target forms; used recasting and elicited imitation techniques to make target forms more salient and develop phonological representations.

Each child received ten, 30 minute sessions over the course of a term with the first author. It was planned that a teaching assistant would attend these sessions and repeat the material once a week. This happened seven times for participant A, but only once for participant $B$. The therapy sessions in

\footnotetext{
${ }^{3}$ Colours for verbs and prepositions have swapped since Ebbels (2007) for the practical reason that verbs most often require coding and yellow was difficult to see.
} 
phase one progressed through the following areas (with more than one area often targeted in each session):

- Reintroduction to Shape Coding (both participants had previously used it to target pronouns).

- Identification of doing words e.g. paint, play and when words e.g. now, yesterday.

- Clarification of present vs. past time.

- Introduction of down arrow to mark present (continuous) vs. past (simple) forms of doing words.

- Sentence completion and error correction tasks in both written and spoken sentences.

- Production of written and spoken sentences with target forms.

Each session began by recapping learning objectives from the previous session and clarifying those for the current session. This was followed by an introductory activity, the main activities, a plenary and an activity/game to end the session. The content of individual sessions varied with the participants' strengths and weaknesses e.g. participant A needed three sessions to learn that 'if the when word is in the past, the down arrow is at the end of the doing word and - ed must be used; participant B needed only one session.

Phase two focused on working in class and at home with communication partners. The therapist carried out four sessions in class, a parent meeting and a session at the participant's home. Activities were given to parents and teachers for carryover in class and at home. Advice was also given on recasting and elicited imitation techniques. Further advice was given to teachers on producing a Shape Coding display for class and on using the system to highlight errors on the board and in written tasks.

\section{Results}

\section{Participant A}


Participant A's assessment scores are shown in Table 2. Changes in the assessment scores were analysed with McNemar chi square tests. His use of target structures was stable during the baseline. He improved significantly on the sentence completion task by the end of the initial therapy period $\left(\chi^{2}=\right.$ $18.05, p<0.01)$ and maintained his progress over the 6 week maintenance period $\left(\chi^{2}=18.05, p<\right.$ 0.01). On each post-therapy assessment, A correctly produced all the treated and untreated verbs. Performance on the conversation task did not change during this period but improved significantly after the generalisation therapy $\left(\chi^{2}=4.9, p<0.05\right)$. The control (do) was stable throughout.

Table 2. Assessment scores for participant A.

\begin{tabular}{ccccccc}
\hline $\begin{array}{c}\text { Structure } \\
\text { assessed }\end{array}$ & Assessment & $\begin{array}{c}\mathbf{1}^{\text {st }} \text { Baseline } \\
\text { Assessment }\end{array}$ & $\begin{array}{c}\mathbf{2}^{\text {nd }} \text { Baseline } \\
\text { Assessment }\end{array}$ & $\begin{array}{c}\text { Post therapy } \\
\text { assessment }\end{array}$ & $\begin{array}{c}\text { Maintenance } \\
\text { Assessment }\end{array}$ & $\begin{array}{c}\text { 9eneralisation } \\
\text { Assessment }\end{array}$ \\
\hline $\begin{array}{c}\text { Regular } \\
\text { past simple }\end{array}$ & $\begin{array}{c}\text { TEGI } \\
+10\end{array}$ & $0 / 20$ & $0 / 20$ & $20 / 20$ & $20 / 20$ & $20 / 20$ \\
$\begin{array}{c}\text { Regular } \\
\text { past simple }\end{array}$ & $\begin{array}{c}\text { Semi } \\
\text { structured } \\
\text { conversation } \\
\text { task }\end{array}$ & $2 / 20$ & $1 / 20$ & $1 / 20$ & $3 / 20$ & $11 / 20$ \\
$\begin{array}{c}\text { Auxiliary } \\
\text { do' }\end{array}$ & $\begin{array}{c}\text { TEGI } \\
\text { (Control) }\end{array}$ & $0 / 20$ & $0 / 20$ & $0 / 20$ & $0 / 20$ & $0 / 20$ \\
\hline
\end{tabular}

Table 3 gives a more detailed breakdown of A's change in responding across the period of therapy. On sentence completion, he inappropriately marked $15 / 20$ verbs with -ing pre-therapy. After therapy he marked all verbs appropriately. On conversation he marked one verb (correctly) pre-therapy and $11 / 20$ post generalisation therapy. 
Table 3. Participant A's responses on sentence completion and conversation tasks pre and post therapy.

\begin{tabular}{ccccccc}
\hline \multirow{2}{*}{ Task } & \multicolumn{2}{c}{-ed } & \multicolumn{2}{c}{-ing } & \multicolumn{2}{c}{ Infinitive } \\
\cline { 2 - 7 } & $\begin{array}{c}\text { Pre } \\
\text { therapy }\end{array}$ & $\begin{array}{c}\text { Post all } \\
\text { therapy }\end{array}$ & $\begin{array}{c}\text { Pre } \\
\text { therapy }\end{array}$ & $\begin{array}{c}\text { Post all } \\
\text { therapy }\end{array}$ & $\begin{array}{c}\text { Pre } \\
\text { therapy }\end{array}$ & $\begin{array}{c}\text { Post all } \\
\text { therapy }\end{array}$ \\
\hline Sentence completion & $0 / 20$ & $20 / 20$ & $15 / 20$ & $0 / 20$ & $5 / 20$ & $0 / 20$ \\
Conversation & $1 / 20$ & $11 / 20$ & $0 / 20$ & $0 / 20$ & $19 / 20$ & $9 / 20$ \\
\hline
\end{tabular}

Further analysis of participant A's results provides comparison of treated vs. untreated items over the initial therapy period. It is not possible to make this comparison over the generalisation period as the therapy was carried out in class with both participants and all 20 items were targeted. Change was the same for treated and untreated items on the sentence completion task. On the conversation task, participant A's scores decreased (from 1 to 0 ) on treated items and increased (from 0 to 1 ) on untreated items. Neither change was significant.

\section{Participant B}

Owing to time constraints, alterations were made to the planned experimental design for Participant B. His generalisation therapy started five weeks into his initial therapy period and ran simultaneously for the remaining five weeks.

Participant B's use of target structures on the sentence completion task did not change during the baseline (see Table 4). His use of target structures on the conversation task and of the control (do) did change over the baseline but these changes were not statistically significant $\left(\chi^{2}=2.25\right.$ on both tasks). At the five week point, when his generalisation therapy started, change was not quite significant on sentence completion $\left(\chi^{2}=3.13\right)$ but was significant on conversation $\left(\chi^{2}=5.82, p<\right.$ 0.05). Change was significant on the sentence completion task by the ten week point when both 
interventions ended $\left(\chi^{2}=5.14, p<0.05\right)$. However, although there was still improvement, his change on the conversation task was just below significance at this point $\left(\chi^{2}=3.13\right)$. His use of control structures did not change over the therapy period.

Table 4. Assessment scores for participant B.

\begin{tabular}{cccccc}
\hline $\begin{array}{c}\text { Structure } \\
\text { assessed }\end{array}$ & Assessment & $\begin{array}{c}\mathbf{1}^{\text {st }} \text { Baseline } \\
\text { Assessment }\end{array}$ & $\begin{array}{c}\mathbf{2}^{\text {nd }} \text { Baseline } \\
\text { Assessment }\end{array}$ & $\begin{array}{c}\text { Pre } \\
\text { generalisation } \\
\text { assessment }\end{array}$ & $\begin{array}{c}\text { Post } \\
\text { generalisation } \\
\text { assessment }\end{array}$ \\
\hline $\begin{array}{c}\text { Regular past } \\
\text { simple }\end{array}$ & $\begin{array}{c}\text { TEGI } \\
+10\end{array}$ & $3 / 20$ & $3 / 20$ & $9 / 20$ & $10 / 20$ \\
$\begin{array}{c}\text { Regular past } \\
\text { simple }\end{array}$ & $\begin{array}{c}\text { Structured } \\
\text { conversation } \\
\text { task }\end{array}$ & $2 / 20$ & $6 / 20$ & $15 / 20$ & $12 / 20$ \\
$\begin{array}{c}\text { Auxiliary 'do' } \\
\text { (Control) }\end{array}$ & $\begin{array}{c}\text { TEGI } \\
+10\end{array}$ & $6 / 20$ & $10 / 20$ & $10 / 20$ & $10 / 20$ \\
\hline
\end{tabular}

The form of Participant B's responses on the two tasks is given in Table 5. In general when he failed to use the past tense, he did not mark the verb at all.

Table 5. Analysis of participant B's responses on the sentence completion and conversation tasks $($ target $=$ '-ed').

\begin{tabular}{ccccccc}
\hline \multirow{2}{*}{ Task } & \multicolumn{2}{c}{-ed } & \multicolumn{2}{c}{-ing } & \multicolumn{2}{c}{ Infinitive } \\
\cline { 2 - 6 } & $\begin{array}{c}\text { Pre } \\
\text { therapy }\end{array}$ & $\begin{array}{c}\text { Post } \\
\text { therapy }\end{array}$ & $\begin{array}{c}\text { Pre } \\
\text { therapy }\end{array}$ & $\begin{array}{c}\text { Post } \\
\text { therapy }\end{array}$ & $\begin{array}{c}\text { Pre } \\
\text { therapy }\end{array}$ & $\begin{array}{c}\text { Post } \\
\text { therapy }\end{array}$ \\
\hline Sentence completion & $3 / 20$ & $10 / 20$ & $1 / 20$ & $0 / 20$ & $16 / 20$ & $10 / 20$ \\
Conversation & $6 / 20$ & $12 / 20$ & $0 / 20$ & $0 / 20$ & $14 / 20$ & $8 / 20$ \\
\hline
\end{tabular}

Participant B's performance on treated and untreated past tense items was quite similar. At the end of the first five weeks of initial therapy, 5 treated and 4 untreated verbs were correct on the sentence 
completion task and 9 treated and 6 untreated correct on the conversation task. As stated above, the data is quoted at this point as both sets of verbs were treated from then on.

\section{Discussion}

Following stable baseline periods, both participants made gains in their use of the target structure (regular past tense) on the sentence completion task after the initial therapy period. Neither improved significantly in their use of the control structure (do). Participant A was fully accurate at using the regular past tense after therapy for both treated and untreated items. Though participant B did less well, his result on sentence completion was significant by the end of therapy. Both participants showed evidence of learning the rule for the regular past tense by showing similar progress on treated and untreated verbs. Thus both participants confirmed hypothesis one - therapy will result in significant improvements in the participants' use of regular past tense morphemes at school with the speech and language therapist. Thereafter the two participants differed in their responses to therapy. Participant A continued in line with hypotheses two and three. He did not improve on the conversation task during the initial therapy but did so when the generalisation therapy was introduced. Participant B was more contrary. Despite responding less well on sentence completion he improved significantly on the conversation task after the first five weeks of initial therapy. One interpretation maybe that his improvement on the conversation task during the baseline period (numerically if not significantly) indicates he was particularly ready to make use of intervention in his more spontaneous speech. However, further analysis is required to confirm this or any other interpretation. For example, more carefully controlled data is required to confirm that phonological factors e.g. phonological form, phonological structural complexity, monomorphemic legality of the 'ed' ending (see Van der Lely 2005 for discussion of these issues) did not play a significant role in either participants' response to intervention. 
Despite the participants' differing responses to the therapy, these results suggests that ten, thirty minute sessions of therapy based around Shape Coding therapy can result in significant improvements in the use of past tense morphemes. Though it would be unwise to generalise to other children from these two contrasting cases, the differences between them may be explained in a number of ways. Firstly, the considerable difference in the nature of their intervention. Whilst $A$ received the planned experimental input, B's generalisation therapy started five weeks into his initial therapy. Hence, he did not receive a maintenance period, which he may have benefitted from to consolidate his learning. Also, for participant $\mathrm{B}$, the two interventions ran simultaneously for the last five weeks of his initial therapy. This may not have suited his learning style, which may have a degree of rigidity considering his diagnosis of ASD. Secondly, the difference in the amount of intervention each participant received may have played a role. Whilst both received an equal amount of intervention from the therapist, A received $7 / 10$ carryover sessions from a TA as part of the initial therapy whereas $B$ received only $1 / 10$. Finally, the participants may simply differ in their ability to use what they learn in therapy and to generalise it. A was more able to apply what he learnt in therapy to sentence completion but required the encouragement of the generalisation therapy before improving on the conversation task. B did not apply his learning as effectively on the sentence completion task but was more successful at generalizing independently. B's response to therapy was more dynamic and may suggest that he progresses more rapidly; however, A's more rigid learning style eventually led to greater gains than did B's. Such results suggest that whilst some children may need help to transfer gains made in therapy to their conversational speech, others may not. Hence, specific work targeting generalisation should be included in the intervention where required.

The therapy used in this study was based around Shape Coding; a metacognitive approach which has been shown to be effective in previous studies (Ebbels 2007, Ebbels et al 2007). However, as 
noted earlier, the therapy was also informed by Fey et al's (2003) 'Ten principles of Grammar Facilitation for Children with SLl'. Hence, as in many clinical interventions, various established methods and principles were included in the therapy such as developing awareness of target forms, providing frequent exposure and frequent opportunities for practising target forms alongside appropriately timed recasts and elicited imitation. In this way, the study builds on the findings of Motsch \& Riehemann (2008) and Finestack \& Fey (2009), who both concluded that a mixed approach, combining metalinguistic and grammar facilitation techniques, may be the most effective way to support the development of grammatical targets.

This research took place during ongoing clinical work with the two participants and aspects of the study reflect the constraints of daily clinical practice e.g. time constraints that changed the experimental design for $\mathrm{B}$, imperfect carryover by teaching staff for both participants (especially B). Such research differs from conventional intervention studies, in which larger numbers of participants are studied and resources are more directly under the control of researchers. In the latter the therapy objectives are often broader and are assessed by standardized measures of language performance. In contrast, clinically based studies are likely to target specific skills as here and to be concerned that these generalise to natural language contexts, represented here by the conversation task. Viewed in this context it may be less surprising that individual participants vary in their response to the therapies offered. Here the two participants both made progress but in different ways, A in line with prior predictions, B unexpectedly.

When considered with the results of other studies, the results of this project suggest further research is warranted into both the effectiveness of Shape Coding therapy and the need for specific activities targeting generalisation. Further investigation should be planned in line with the recommendations made in Fey \& Finestack's (2009) five phase model of research and development in child language 
intervention. It should continue to address the issues mentioned in Ebbels (2008) i.e. the need for more intervention studies focusing on school aged children, specific target areas, maintenance and generalisation of targets. As stated previously, the understanding and use of grammar is a key area of difficulty for some children with language impairments and the effect this has on academic and social achievement is well established (Proctor-Williams, 2009). Consequently, further investigation is required to assess the reliability and validity of the results from this small study of clinical practice.

\section{References}

Bishop, DVM (2004) Specific language impairment: diagnostic dilemmas. In Van Balkom H, Verhoeven LT Classification of developmental language disorders: theoretical issues and clinical implications. Lawrence Erlbaum Associates Inc: 309-326.

Bolderson S, Dosanjh C, Milligan C, Pring T and Chiat, S. (2011) Colourful Semantics: a clinical investigation. Child Language Teaching \& Therapy 27(3): 344-353.

Bryan A (1997) Colourful Semantics. In S. Chiat, J. Law, \& J. Marshall, (Eds.), Language disorders in children and adults: psycholinguistic approaches to therapy, London: Whurr.

Conti-Ramsden G \& Botting N (1999) Classification of children with specific language impairment: longitudinal considerations. Journal of Speech, Language and Hearing Research 42: 1195-1204.

Conti-Ramsden G \& Botting N (2001) Psycholinguistic Markers for SLI. Journal of Child Psychology 42(6): 741-748.

Doran GT (1981) There's a S.M.A.R.T. way to write management's goals and objectives. Management Review 70(11): 35-36.

Ebbels S (2007) Teaching grammar to school aged children with Specific Language Impairment using Shape Coding. Child Language and Teaching Therapy 23(1): 67-93.

Ebbels S (2008) Improving grammatical skill in children with SLI. In Norbury CF, Tomblin B \& Bishop D (Eds) Understanding Developmental Language Disorders. Psychology Press: 149-165.

Ebbels SH, Van der Lely HKJ and Dockrell JE (2007) Intervention for Verb Argument Structure in Children with Persistent SLI: A Randomized Control Trial. Journal of Speech, Language, and Hearing Research 50: 1330-1349.

Fey ME, Long SH \& Finestack LH (2003) Ten Principles of Grammar Facilitation for Children with Specific Language Impaiments. American Journal of Speech-Language Pathology 12: 3-15. 
Fey ME \& Finestack LH (2009) Research \& development in children's language intervention: A 5phase model. In Schwartz RG (Ed) Handbook of child language disorders. New York: Psychology Press: 513-531.

Finestack LH \& Fey ME (2009) Evaluation of a Deductive Procedure to Teach Grammatical Inflections to Children With Language Impairment. American Journal of Speech-Language Pathology 18: 289-302.

Leonard L B, Camarata SM, Brown MPB et al (2008) The acquisition of tense and agreement morphemes in children with SLI during intervention: Phase 3. Journal of Speech, Language and Hearing Research 51: 120-125.

Marchmann VA, Wulfeck B \& Weismer SE (1999). Morphological Productivity in Children with Normal Language and SLI: A Study of the English Past Tense. Journal of Speech, Language and Hearing Research 42: 206-219.

Motsch HJ \& Riehemann S (2008) Effects of 'Context-Optimization' on the acquisition of grammatical case in children with specific language impairment: an experimental evaluation in the classroom. International Journal of Language \& Communication Disorders 43 (6): 683-698.

Proctor-Williams K (2009) Dosage and Distribution in Morphosyntax Intervention: current evidence and future needs. Topics in Language Disorders 29 (4): 294-311.

Raven JC (1998) Raven's Progressive Matrices. Pearson UK.

Rice ML, Tomblin BJ, Hoffman L et al (2004) Grammatical Tense Deficits in Children with SLI and Nonspecific Language Impairment: Relationships With Nonverbal IQ Over Time. Journal of Speech, Language and Hearing Research 47: 816-834.

Rice ML \& Wexler K (1996) Toward tense as a clinical marker of specific language impairment in English-speaking children. Journal of Speech \& Hearing Research 39 (6): 1239-57.

Rice M \& Wexler K (2001) Rice-Wexler Test of Early Grammatical Impairment. The Psychological Corporation.

Rice M, Wexler K \& Cleave PL (1995) Specific language impairment as a period of extended optional infinitive. Journal of Speech \& Hearing Research 38 (4): 80-63.

Semel E, Wiig E \& Secord E (2006) Clinical Evaluation of Language Fundamentals 4. Harcourt Assessment.

Seef-Gabriel B., Chiat S \& Pring T (2012) Intervention for co-occuring speech and language difficulties: Addressing the relationship between the two domains. Child Language Teaching and Therapy 28 (1): 123-135.

Tomblin BJ, Records LN, Buckwalter P, Zhang X, Smith E \& O'Brien M (1997) Prevalence of specific language impairment in kindergarten children. Journal of Speech-Language-Hearing Research 40: $1245-1260$. 
Van der Lely HKJ (2005) Grammatical-Specific Language Impairment (G-SLI): Identifying and Characterising the G-SLI Subgroup. Frequencies 17 (3): 13-20. 